\title{
Más allá de la Captura del Estado: formas híbridas de estatalidad desde el caso subregional del Catatumbo - Colombia.
}

\section{Beyond State Capture: hybrid forms of statehood from the subregional case of Catatumbo - Colombia}

\section{Henry Yesid Ortega Palacio(*)}

Pontificia Universidad Javeriana - Bogotá

ORCID: 0000-0002-7515-7120

Fecha de recepción: 20 de mayo

Fecha de aceptación: 31 de julio

ISSN en línea:

Ortega Palacio, H. (2019) « Mas alla de la Captura del Estado: formas hibridas de estatalidad desde el caso subregional del Catatumbo - Colombia». Politai: Revista de Ciencia Política, Año 10, primer semestre,pp-169-197

DOI: https://doi.org/10.18800/politai.201901.006

\footnotetext{
* Politólogo de la Pontificia Universidad Javeriana - Bogotá. Hoy en día se desempeña como Investigador Auxiliar del equipo de Estado y Conflicto del Centro de Investigación y Educación Popular -CINEP. Ha desarrollado diversas investigaciones centrándose en los movimientos sociales, conflicto armado y la temática de sustitución de cultivos de uso ilícito, sobre todo en la región del Catatumbo. Asimismo, cuenta también con un par de artículos en materia de construcción de paz; y en la actualidad, en el marco del trabajo del CINEP, participa en investigaciones de minería y conflicto armado en Nariño, y reestructuración de órdenes sociales armados en algunas zonas de Colombia.
} 


\section{Sumilla}

Múltiples estudios abordan el Estado en Colombia como caso especial en América Latina, entre variadas razones, por la particular coexistencia de una democracia longeva y aparentemente estable junto a periodos prolongados de violencia armada y marginalidad regional. Para el caso colombiano, Luis Jorge Garay ha sido un autor clave en el uso de la noción de Captura del Estado mientras otros, como Fernán González, proponen lecturas contrarias que abordan la cuestión a partir de conceptos tales como Presencia diferenciada del Estado y Gobernabilidades híbridas. La presente investigación recoge estas discusiones, optando preferentemente por el segundo autor en mención, para dar un panorama de la hibridez y las formas propias de gobernabilidad en regiones donde el Estado es, ante todo, un jugador más en las constantes disputas por poder.

Como asidero de estas discusiones, la investigación toma por caso al Catatumbo, región marcada por el conflicto al nororiente de Colombia. Allí, un vigente remezón causado por el desarme de las Farc puso en disputa los órdenes políticos generado por grupos armados -aún beligerantes-, la población civil a través de fuertes movimientos sociales y el Estado. Los hallazgos dan cuenta de maneras propias de poder en regiones de estas características con la posibilidad misma de extender elementos analíticos a otros casos del país y del resto de Latinoamérica.

Palabras clave: Gobernabilidad híbrida, Catatumbo, Estado, Captura del Estado, construcción de paz. 


\begin{abstract}
Multiple studies address the state in Colombia as a special case in Latin America, among many reasons, due to the particular coexistence of a long and apparently stable democracy accompany with prolonged periods of armed violence and regional marginality. For the Colombian case, Luis Jorge Garay has been a key author in the use of the notion of Capture of the State while others, like Fernán González, propose contrary readings that try to approach the question from concepts such as differentiated Presence of the State and hybrid Governance. The present research gathers these discussions, opting preferably for the second author in mention, to give a general perspective of the hybridity and the own forms of governability in regions where the state is, first of all, another player in the constant disputes of power.
\end{abstract}

As a basis for these discussions, the research takes Catatumbo as a case, a region marked by the conflict in northeastern Colombia. There, a current tremble caused by the disarmament of the Farc put in dispute the political orders generated by armed groups - still belligerent - and the civilian population through strong social movements and the State. The findings show the particular ways of power in regions of these characteristics with the possibility of extending these analytical elements to other cases in the country and the rest of Latin America.

Keywords: Hybrid governance, Catatumbo, State, State Capture, peace building. 


\section{Introducción}

Comprender las causas de una promesa incumplida es quizá la razón principal para los estudios sobre el Estado en Colombia y América Latina. Para el caso colombiano, las búsquedas de causales de los problemas del Estado han venido acompañadas, además, con la búsqueda de las causales del conflicto armado y en general del fenómeno de la violencia en el país. Y no es para nada sorprendente, de suyo la existencia de una guerra civil prolongada habla de la incapacidad del Estado colombiano para hacerse con una de las principales características del Estado moderno: el monopolio de la fuerza.

Pero este no es el único embrollo. Se requiere comprender las implicaciones sociales y políticas del conflicto en su relación con los problemas de materialización de las funciones del Estado, más allá del monopolio de la fuerza. Desde el Estado mismo y su relación con la violencia, aparecen así investigaciones que analizan la manera como este debe mediar con la existencia de formas otras de organización política, que sobrepasan la idea del Estado como mediador máximo y principal de las interacciones de la sociedad civil en su búsqueda por el bienestar común.

En este sentido, para el caso colombiano han surgido variedad de investigaciones que enuncian elementos causales y explicativos del conflicto armado y los problemas del Estado, donde destacan, de tiempo atrás hasta hoy en día, trabajos como La Violencia en Colombia de Guzmán, Fals Borda y Umaña, las investigaciones sobre la Precariedad del Estado de Daniel Pecaut, Colapso parcial del Estado de Paul Oquist, la Captura y Reconfiguración cooptada del Estado de Luis Jorge Garay o los trabajos en el 2015 de la Comisión Histórica del Conflicto y sus Víctimas. Varias de estas tienen fallas argumentativas sobre todo por la dificultad de integrar un análisis multivarial más complejo, que dé cuenta del panorama actual del Estado en Colombia y Latinoamérica; permitiendo pensar formas de acción acompañadas de una rigurosa reflexión teórica y conceptual.

Con este telón de fondo, el propósito de este artículo es hacer una lectura de las dimensiones de los problemas del Estado en Colombia, problematizando la manera en la que conceptos como la Captura del Estado recogen tan sólo una cara de un poliedro confuso; tratando así de ir un poco más allá. Se retoma para esto los conceptos de Presencia diferenciada del Estado (González, Bolívar y Vázquez, 2003) como lectura histórica de su formación, 
y de Gobernabilidades híbridas (González, 2014) para evidenciar el contexto, que de antes y actualmente, tiene el Estado colombiano ante sí; más aún ante la coyuntural necesidad de darle un asidero en la realidad al último proyecto de apertura democrática en el país: el Acuerdo Final que puso fin al conflicto armado con la guerrilla de las Farc-Ep.

Este propósito se concretará a través de la presentación del caso subregional del Catatumbo, zona históricamente afectada por el conflicto armado y con evidente ausencia, o, dicho sea de paso, presencia diferenciada del Estado. La presentación de este caso junto al marco teórico y conceptual, se decanta en un análisis propositivo de las maneras como el Estado colombiano debe abordar la hibridez de sus contextos, partiendo de un cuestionamiento más que de sus actos, de su propia naturaleza. Los elementos propositivos pueden ser vistos en clave latinoamericana y expandirse para una lectura comparada a los demás países de la región.

Con todo lo anterior sobre la mesa, el artículo se divide a continuación en tres secciones. La primera hace una problematización de los componentes teóricos y conceptuales usados para la investigación sobre el Estado en Colombia; el segundo apartado hace la presentación del caso subregional del Catatumbo, haciendo mención expresa de las gobernabilidades armadas y civiles que hacen presencia allí; y por último un apartado con las propuestas analíticas, que se basan en la profundización del carácter híbrido de los contextos donde el Estado es tan solo, y debería seguir siendo, otro actor más en medio de múltiples formas de ser y hacer del quehacer político y social. 


\section{Más allá de la Captura del Estado ${ }^{1}$.}

Previo al abordaje de las discusiones sobre los problemas del Estado en Colombia se requiere puntualizar ciertas acepciones. Para los efectos presentes, el Estado se asume como la entidad política preponderante cuyo modelo contiene como supuesto el monopolio, no solo de la fuerza, sino también de la guía sobre elementos varios de las poblaciones y territorios sobre los que ejerce su capacidad regulatoria; elementos como un proyecto de identidad cultural, el modelo de desarrollo, entre otros. De esta pretensión sobre el monopolio de ciertos elementos de la vida social, emergen también ciertas responsabilidades de esta entidad política expresadas a través de los fines a los que apuntan sus acciones. Entre tantas, en materia general se encuentran la garantía de seguridad, la provisión de justicia y de mínimos de estabilidad y calidad de vida a través del suministro de servicios públicos (González, 2014). Según se vaya ajustando el modelo de Estado van primando unos elementos sobre otros, como la primacía de un orden jurídico en el Estado de Derecho, o la salvaguarda de unos mínimos de reconocimiento y dignidad en el Estado Social de Derecho.

Cabe aquí una mención del concepto de sociedad civil. Entendida como una esfera separada del Estado, muchas veces se hace una suerte de equivalencia de la sociedad civil con el concepto de ciudadanía, o por lo menos se supone a la sociedad civil como aquella que agrupa a los ciudadanos de un territorio. Esta interpretación, aunque adecuada para unos fines, es limitada y se avala en una visión normativa de esta esfera no estatal que no necesariamente responde a la realidad de Colombia y Latinoamérica.

El concepto de ciudadanía supondría la vigencia y circunscripción de la población en el marco de derechos reconocidos en el conjunto, manifestados en un ordenamiento jurídico y bajo la salvaguarda del accionar del Estado.

1 Este apartado hace un barrido a través de múltiples variables, temas y conceptos analizados para el caso colombiano y en general para el análisis de casos de países con características similares a Colombia. Aunque parezca atrevido y superficial el repaso y la enunciación de estas propuestas teóricas y conceptuales; el fin último de este apartado, y en general del artículo, es mostrar que los resultados de todas estas investigaciones hacen parte de una misma lectura de una realidad con múltiples aristas, y que por tanto es necesario establecer una lectura esquemática del problema donde se les sienten a todas a conversar. 
Pero ya que la vigencia de estos derechos es disímil entre diversos sectores, cuestionar la categoría de ciudadanía vendría siendo útil, no para suprimirla, sino para ampliar el concepto de sociedad civil; negar la equivalencia entre ambos al comprender que en la realidad colombiana y latinoamericana, múltiples grupos de personas se encuentran por fuera de lo que podría encajar en el concepto clásico de ciudadanía, pero no por ello dejan de ser parte del cúmulo de la sociedad civil; contenida así con formas más heterogéneas.

Esto en cuanto a las precisiones conceptuales. Enunciados ya los fines a los que apunta la noción de Estado y las responsabilidades que este proyecto asume, la preocupación por un Estado incapaz de satisfacerlas, sumergido en constantes tormentas que imposibilitan sus rumbos, ha sido un elemento de mucho interés para variadas investigaciones que han apuntado múltiples explicaciones.

Algunas de estas ya fueron mencionadas en el apartado introductorio, ejemplo: Colapso parcial del Estado de Paul Oquist o la Captura y Reconfiguración cooptada del Estado de Luis Jorge Garay. Pero dichos postulados poseen una falencia argumentativa al ser investigaciones cuyas ópticas, unas más que otras, desconocen el carácter histórico del Estado en la realidad colombiana y latinoamericana. Suponen una lectura que entiende al Estado como una realidad dada en la que los problemas de materialización de sus fines se presentan como una afrenta a sus instituciones, analíticamente universales, o la cooptación de las mismas en todo espacio y tiempo.

Abórdense aquí ciertos contenidos de estas propuestas de análisis y el porqué de sus inconvenientes. El concepto de Colapso parcial, como se puede ver en González (2003 y 2014), obedece a la visión más ahistórica de los mencionados debido al esquema argumentativo que requiere para su validez. Centrándose en la búsqueda de causales explicativas para el periodo de la Violencia de los años cincuenta, Paul Oquist apuntala el Colapso parcial del Estado como

“crisis e inoperancia de las instituciones establecidas, la pérdida de legitimidad del Estado, la apelación del mismo a prácticas terroristas la ausencia física del Estado en grandes regiones del país y las contradicciones dentro del aparato armado del mismo” (1978).

Su desacierto como explicación de la incapacidad del Estado está en que dicho argumento supone la existencia previa de instituciones más o menos 
sólidas, que posteriormente colapsan; supuesto que desconoce -a pesar de mencionarlo el mismo Oquist- la no existencia de tales instituciones estatales en todo el territorio colombiano con alcances y capacidades diferenciadas, ni la diferenciación temporal en la manifestación de estas capacidades ${ }^{2}$.

Por su parte, la Presencia diferenciada del Estado (González, 2003; González, Bolívar y Vázquez, 2003) responde al vacío de lectura histórica del anterior concepto, al comprender el Estado como un proyecto en construcción y por tanto logrando evidenciar las variaciones de espacio y tiempo en las capacidades para la realización de sus fines.

Para el caso colombiano, González, Bolívar y Vázquez (2003) exponen cómo las regiones se han insertado de manera paulatina en el quehacer nacional, jugando un papel en ello el conflicto armado y las múltiples expresiones de violencia. Sin embargo, que una región tenga un grado de inserción significativo a nivel nacional no es criterio único para comprender la forma de interacción entre el Estado y estos territorios y con sus organizaciones civiles y armadas. Como criterio formal, dar un visto bueno a la presencia del Estado a través de ciertas instituciones -principalmente su lanza de batalla ha sido la Fuerza Pública- no implica la garantía de las responsabilidades estatales y la vigencia de derechos. Además, queda pendiente, y el concepto de Presencia diferenciada no lo obvia, la interacción con las otras formas regulatorias para definir la consolidación de la promesa de cumplir, por lo menos, con los fines de seguridad y justicia.

El contexto es variadamente complejo y varias investigaciones y conceptos, además del de Presencia diferenciada, han ido abordando tales problemáticas. Por su parte la Captura del Estado, con Luis Jorge Garay como máximo exponente en Colombia, analiza las relaciones de cooptación de privados hacia el sector público a través de actos de soborno, presión

${ }^{2}$ Se erraría también en la dimensión temporal en hacer una lectura lineal, progresiva y en expansión continua de las capacidades del Estado colombiano. Aunque en muchos espacios el llamado es a que estas mejoren, y sin duda alguna es evidente una mayor integración del Estado y las regiones del país así como un robustecimiento de variadas capacidades; quedarse con la lectura de la mejora lineal y progresiva en el tiempo de las capacidades del Estado llevaría a no tener que cuestionar sus retrocesos y también la forma como se da su relación con los territorios y la sociedad civil, ni tan siquiera abordar sus dificultades desde la complejidad del asunto, sino tan solo dedicarse a esperar: esperar que algún día el Estado, en su progreso continuo hacia el futuro, llegará por si solo a cumplir sus promesas. 
política o intimidación. Estos privados ponen al servicio de sus intereses la capacidad del Estado de agenciar y proponer discursiva y materialmente el bienestar general.

En el proceso de consolidación del Estado de Derecho podrán surgir diversos actores, algunas veces incluso tanto o más fuertes que el mismo Estado en el nivel central o especialmente en los niveles territoriales y locales, interesados en suplantarlo y dominar el aparato estatal en instancias decisivas para lograr los intereses particulares de los actores captores y no necesariamente para el bienestar colectivo (Garay, Salcedo, De León y Guerrero, 2008, p. 53).

Junto a esto, Garay et al. (2008) aciertan en la forma como aterrizan al caso colombiano el concepto e incluyen a los grupos armados como actores que le dan una nueva dimensión a la Captura, ampliando la visión clásica que se limitaba a los grupos de interés privados casi siempre empresariales. Pero centrarse en la Captura del Estado como matriz de análisis preponderante para comprender, no solo los problemas sino la naturaleza del Estado, en Colombia y América Latina, es un error.

En primer lugar porque la Captura del Estado sería tan solo una de varias problemáticas de un espectro que se explicará más adelante. En segundo término, porque no todas las formas de acción por parte de los actores fuera del Estado -la variada sociedad civil- buscan materializarse en el marco de las esferas estatales, incluso si están en constante interacción con ellas, ni mucho menos sus acciones autonómicas van en detrimento del bienestar colectivo.

Buscar suplantar o ejercer por autonomía funciones que 'competen' al Estado, sean loables o no los intereses que respaldan esta búsqueda, no necesitan siempre de la cooptación de los aparatos estatales precisamente por su carácter independiente. Es por esto que la idea de Captura del Estado, aunque acertada y necesaria para los casos de interés particular que se aprovechan de este; no recoge la complejidad de los escenarios.

Hasta acá se hacen visibles dos esferas para clasificar los problemas o complejidades de realización de los fines del Estado: i) al interior del aparato estatal, es decir, en el marco de sus instituciones, burocracias, etc.; y al exterior del aparato estatal, es decir, en su relación con los territorios donde aparecen formas de regulación y provisión de servicios diferentes a las estatales. 
Al interior del aparato estatal se evidencian dos problemáticas: la Captura del Estado y el Clientelismo. Las implicaciones del primer fenómeno ya han sido expuestas. El segundo por su parte, que cuenta como grandes exponentes los trabajos de Leal y Dávila (1990 y 2010) y Gutiérrez Sanín (2007), muestra las redes de poder generadas a partir de políticos locales y regionales que van repartiéndose entre ellos el manejo presupuestal y laboral de los órganos del Estado, y el manejo y prestación de los servicios públicos, para transar por votos con sus electores.

La diferencia principal entre clientelismo y captura del Estado (con la corrupción como máxima expresión) es el uso dado a los aparatos del Estado: mientras la captura es el uso de los aparatos estatales para fines privados, el clientelismo es el uso de los aparatos estatales para fines políticos. Muchas veces los actos enmarcados en un fenómeno u otro son difusos, sin embargo, bien diferenciados, el clientelismo a su manera supone ante todo una dimensión funcional de los aparatos del Estado; a través de una relación disfuncional, de nuevo, con el concepto de ciudadanía, puesto que ponen a la población en una situación de cliente (Gutiérrez Sanín, 2007): los derechos, servicios, etc. a los que accede, no los accede por su condición de ciudadanía sino por su condición de cliente frente a un grupo político.

Ahora bien, lo mismo que el clientelismo se pone en zona gris con los actos de captación del Estado; este posee dos dimensiones que le permiten ubicarlo como práctica al interior y al exterior del aparato estatal. Y esto es así, porque el clientelismo pone de manifiesto no sólo una relación clientelar de la población respecto a los derechos y servicios ofrecidos por el Estado; también existen maneras de relación clientelar que crean formas regulatorias en relación y con uso de las capacidades y recursos del Estado, pero que se pudiesen leer, dada su naturaleza, por fuera del alcance mismo del aparato estatal, pertenecientes así gobernabilidades en sí mismas. Son manifestaciones de poder local y regional donde la presencia diferenciada del Estado tiene un grado mayor. Ejemplo de esto son los poderes de corte gamonal (Sánchez y Meertens, 1983): en estos casos, los políticos locales y regionales, en un modelo de poder y prestigio relacionado con la tenencia de la tierra, administran la prestación de las funciones estatales en representación del Estado, pero por fuera de la esfera estatal, casi, podría decirse, que a título propio. 
Hay otras dos formas de complejidades o 'problemas' para el Estado hacia el exterior de la esfera estatal: la regulación armada y la regulación comunitaria $^{3}$. Sobre la primera, evidenciando el componente político y social del conflicto armado en Colombia, múltiples investigaciones científicas, periodísticas, literarias y demás; se han dado a la tarea de develar las formas como los grupos armados interactúan con las comunidades donde se encuentra, sus ámbitos de regulación, la promoción de modelos de sociedad específicos, etc ${ }^{4}$.

En tiempos de transformación y búsqueda de escenarios de paz, esta es una realidad esencial. En aras de incidir en la reducción de la violencia, evidenciar que los grupos armados poseen un nivel de injerencia tal en los territorios donde hacen presencia, más allá de una pretensión depredadora de recursos; es un imperativo para la acción sobre estas realidades. Estos grupos por lo general terminan impartiendo reglas en la comunidad, brindando seguridad y dirimiendo conflictos de la vida cotidiana.

En Colombia, la Presencia diferenciada del Estado y el poder regulatorio de los grupos armados, generan un contexto analizable a la luz de concepto de Órdenes políticos en tiempos de guerra de Paul Staniland (2012). Este concepto es bastante útil, sobre todo para leer las tensiones y transacciones entre grupos armados, legales o ilegales; pero deja por fuera la variable no armada. Estos órdenes sociales, y toda propuesta de transformación de las realidades de estos territorios, debe tener en cuenta el papel de la sociedad civil.

Así se llega a la última complejidad hacia el exterior del Estado, y es la regulación comunitaria. Teniendo en cuenta el caso que se presentará, las regulaciones comunitarias presentes en Colombia tienen por lo menos tres manifestaciones, en categorías que no están exentas de intersección: regulación étnica, con las comunidades indígenas y afrodescendientes que poseen formas medianamente autónomas de vida comunitaria; regulación comunal, a través del uso de las Juntas de Acción Comunal como forma de

3 Este contexto de tres formas regulatorias: clientelista, armada y comunitaria; desembocará más adelante en el concepto de gobernabilidades híbridas propuesto por Fernán González (2016).

${ }^{4}$ Una de las investigaciones más recientes sobre el papel regulador de los grupos armados le establece incluso un término muy adecuado para sus tratamiento: Rebelocracia (Véase Arjona, 2016). 
organización; y regulación social, a través de movimientos sociales que emprenden "acciones colectivas [permanentes] comprometidas con el cambio social” (Cepeda, 2015).

Hay que apuntar una particularidad. En su relación con el Estado estas regulaciones de la vida comunitaria son objeto de cierta institucionalización: el Estado reconoce a los resguardos indígenas, consejos comunitarios afrodescendientes, Juntas de Acción Comunal o movimientos campesinos. Les exige y otorga una personería jurídica como requisito para la interacción con el aparato estatal, pero a pesar de la traducción de estas interacciones a un lenguaje más cómodo para el Estado; la naturaleza de estas formas regulatorias pone en entredicho el concepto clásico del Estado y le da una dimensión propia del fenómeno latinoamericano ante el cual la estatalidad debe adaptarse.

Así, muchas de estas complejidades o 'problemas' hacia el exterior del Estado pueden ser vistas como formas otras de estatalidad, unas más que otras; como las ejercidas los grupos armados, pues ellos cumplen con muchos de los símiles del orden estatal, toda vez que la base de su poder regulatorio se fundamenta también en la existencia de un poder coercitivo y cumplen con la satisfacción de necesidades de seguridad y justicia. La lectura sobre la regulación de tipo clientelista queda en una zona gris, entre dentro y afuera, pues no es más que otra forma de funcionamiento del Estado, quizá una no muy virtuosa, pero no alcanza a salirse de lo que la estatalidad implica, y en los casos en que lo hace no se puede hablar de un nivel pleno de paraestatalidad. Y, en el caso de las regulaciones comunitarias, lo que se encuentra es un panorama de reclamo por ejercicios autónomos de regulación de la vida social pero sin recurrir a la suplantación o creación de nuevas formas estatales plenamente ${ }^{5}$.

Todo lo anterior, que fue categorizado como complejidades al exterior de la esfera estatal, es el desarrollo de lo que ya González (2016) llamó formas regulatorias (autoritarias, clientelistas o comunitarias), enmarcadas en su propuesta conceptual de Gobernabilidades híbridas, como interpretación del escenario que enfrenta el Estado colombiano, en particular con la coyuntura

\footnotetext{
${ }^{5}$ Como apunta Rita Laura Segato en su libro La nación y sus otros (2007), no recurre a dicha suplantación de la estatalidad, puesto que sus fines, su maneras de organizarse de gestionar la vida comunitaria son formas otras distintas a la lógica del Estado.
} 
del Acuerdo de paz, y la necesidad de reconocer estas formas regulatorias para construir audazmente junto a ellas la denominada paz territorial.

González define la Gobernabilidad como la "capacidad del gobierno para responder eficazmente a los problemas sociales" (2016). Sin embargo, aquí hay un vacío que de llenarse, permite responder al supuesto de 'formas de estatalidad' y al tiempo hacer honor a la propuesta de gobernabilidades híbridas escrita en plural. Si el concepto de gobernabilidad atañe a la capacidad para responder a los problemas sociales, este no debe limitarse a la capacidad del Gobierno para responder a estos problemas. Se debe hablar que tales formas regulatorias (autoritarias, clientelistas o comunitarias) manifiestan en sí mismas formas de gobernabilidad a las que se llamarán formas de gobernabilidad autónomas. Son las formas de gobernabilidad autónomas las que en trabajo conjunto con la gobernabilidad estatal, y entre ellas, generan la posibilidad de gobernabilidades híbridas. Es decir, la capacidad del gobierno, de los grupos armados, los políticos clientelistas y las comunidades; de responder eficazmente a los problemas sociales; con la particularidad que en muchos territorios, todas estas formas de gobernabilidad interactúan entre sí, en relaciones más o menos conflictivas, dando el carácter de hibridez a estos contextos.

Hasta aquí, el popurrí teórico al que se ha hecho mención deja en firme la necesidad del abordaje híbrido de las funciones que normalmente le competen al Estado, a fin de reconocer las realidades territoriales propias como la que se presentará a continuación.

\section{El caso subregional del Catatumbo.}

El Catatumbo es una subregión al nororiente de Colombia en el departamento de Norte de Santander, que agrupa a 11 municipios de este departamento. Caracterizada por una topografía escabrosa y ecosistemas selváticos, la subregión ha sido uno de los focos de interés en cuanto al conflicto armado en el país por la mención constante que se hace por lo que allí ha sucedido y sigue sucediendo.

En resumidas cuentas posee las siguientes características: en materia del conflicto armado ha tenido presencia histórica de todos los grupos armados, desde el inicio de este periodo de violencia en la década de los 60, actualmente es una regiones con mayores cultivos de hoja de coca en el país, además de contar con una gama más amplia de economías ilegales que 
comprenden la comercialización de los estupefacientes y el contrabando de alimentos, armas y combustibles; esto debido a su también condición de frontera con Venezuela en pasos bastante porosos y poco controlados.

Su posición geográfica la hace un punto estratégico, pues no sólo es frontera con Venezuela, sino que puede conectarse con el Sur del Cesar iniciando un corredor que pasa por el Sur de Bolívar en el Magdalena Medio, sigue por el Nororiente antioqueño y va a dar al Urabá en el extremo noroccidental de Colombia. Pero su economía no se expresa únicamente en la ilegalidad. También ha sido una despensa agraria importantísima sobre todo para el departamento de Norte de Santander; y es también un enclave de explotación petrolera y sembradíos de monocultivos legales como la palma de aceite; economías estas que no han dejado de tener un impacto y relacionamiento complejo con la región (Cinep, 2017) ${ }^{6}$.

Las dinámicas de poblamiento han tenido varias etapas. De un lado, la subregión ha sido habitada históricamente por el pueblo indígena Motilón Barí, actualmente habitando los resguardos Catalaura y Motilón-Barí. Las comunidades de campesinos mestizos empezaron a llegar a comienzos del siglo XX por la instalación de un enclave petrolero, entregado por el Estado en concesión a un político prominente de la región ${ }^{7}$. En adelante, se presentarían dos oleadas de colonización más, movilizadas por razones políticas y de búsqueda de oportunidades económicas y de tierras: en 1950, la violencia bipartidista en el país movilizó a algunos campesinos hasta esta zona buscando apartarse de sus impactos y en 1980 la bonanza cocalera terminó de consolidar las etapas más fuertes de la colonización (Aponte, 2012 y Carvajal, 2016).

El conflicto armado complementa el panorama de la región. Allí se dio una inserción temprana por parte de las guerrillas de las Farc, ELN y EPL en la década de los sesenta y setenta. Más tarde en los noventa, aun cuando todos los demás frentes del país se desmovilizaron, el frente del EPL en el territorio se mantuvo en funciones, incluso a hoy en día. La incursión paramilitar se da

\footnotetext{
${ }^{6}$ Esta economía se relaciona con prácticas de acumulación de la tierra resultante de la compra masiva de predios, pero también del aprovechamiento para ello de condiciones de despojo y manejo de precios producto del desplazamiento de la población. Se apunta que varios políticos regionales han participado de la creación de contextos favorables para el ejercicio regular y legal de esta economía (Entrevista experto regional, 2019).

${ }^{7}$ Atisbos de hibridez.
} 
a finales de los noventa, generando un alza significativa en la intensidad del conflicto armado en la región. Posterior a su desmovilización en el 2005 se dio la aparición de Grupos Armados Posdesmovilización (Vázquez, 2016). En la actualidad, el panorama del conflicto se mantiene vigente, ya que el desarme de las Farc en el proceso de paz no significó una paz completa con el ELN y el EPL, además de un reciente resurgimiento de una disidencia del Frente 33 de las Farc.

Este panorama presenta por lo menos cuatro mapas o territorialidades que se intersectan y donde cada uno de los grupos pertenecientes a la región ejercen a su manera su gobernabilidad. Lo interesante es que no existe en todos los casos una delimitación territorial sólida e invariable para el ejercicio de estas prácticas de gobernabilidad, salvo aquellas proporcionadas por la división político-administrativa del Estado en la que incluso se ven acogidos los indígenas, al tener resguardos delimitados en últimas por la autoridad estatal $^{8}$. Así las cosas, si se desea hacer una lectura por zona de influencia del ejercicio de gobernabilidades se requiere pensarse una mixtura desde los municipios (entidad político-administrativa estatal), presencia de grupos armados, influencia de movimientos campesinos y resguardos indígenas. Y se van dando así más elementos de la hibridez del caso.

\subsection{Panorama de gobernabilidad armada.}

Como se mencionó, los grupos armados en la región han hecho presencia histórica en la región desde los inicios del conflicto armado. La forma como han hecho presencia ha sido la siguiente:

De las Farc -en su momento como grupo armado-: Frente 33, del ELN: Frente Nororiental, el EPL o pelusos: Frente Libardo Mora Toro, los paramilitares: Bloque Catatumbo, el Estado a través de la Trigésima Brigada, y actualmente grupos como las Águilas Negras, los Rastrojos y los Urabeños (Ortega, 2018, p.43).

Los órdenes políticos en tiempos de guerra en la región han sido determinados, dada la temporalidad de su presencia, mayoritariamente por las guerrillas. La gobernabilidad armada por parte de estos grupos, extendida por toda la región con límites y fronteras más bien cambiantes, se expresa en

\footnotetext{
${ }^{8}$ Aunque hay que apuntar que ellos también rompen este esquema por las formas de habitar sus espacios e incluso por su condición de binacionalidad con Venezuela.
} 
el control variado de diversas prácticas de la región. Ellos ejercen injerencia en las cadenas de producción de las economías ilícitas del narcotráfico y contrabando, repartiéndose en muchas ocasiones los puntos de incidencias según el territorio y los eslabones en las economías en cuestión.

Pero estas injerencias van más allá de los quehaceres económicos, legales o ilegales, donde se ven involucradas muchas poblaciones que no tienen otras oportunidades laborales estables debido a las condiciones de marginalidad de la región. Además de influir y respaldar proyectos políticos, proponiendo agendas de reclamo desde las cuales justifican su continuidad en armas; estos grupos terminan supliendo al Estado ante las necesidades de seguridad y justicia de la población.

Para ejemplificar lo anterior téngase en cuenta cómo en municipios de la región, unos más que en otros, existen normas de comportamiento al interior de los poblados. A este respecto los grupos armados juegan un papel de autoridad policial, aun cuando la Policía Nacional posee estaciones por lo menos en el casco urbano central ${ }^{9}$. Estas normas son variadas. Por ejemplo, en algunos de los municipios en las fiestas del pueblo están prohibidas las riñas entre las personas, más aún en estado de embriaguez; faltar a esta regla conlleva multas y castigos a sus participantes. O incluso, en las maneras como se habita el día a día, las casas tienden a permanecer con las puertas abiertas y los automóviles y demás sin seguros, puesto que el robo está expresamente proscrito; incumplir esta norma supondría el destierro o la muerte. Existe también regulación del uso de armas al interior de los cascos urbanos. Verbigracia, en entidades del Estado que por defecto tienen sus propios servicios de vigilancia, varios de estos celadores en ejercicio de su labor de vigilia y control en las instalaciones de estos lugares, no se encuentran armados pues existe un veto al uso de armas por parte de estos grupos (Observación y entrevistas pobladores, 2018).

\subsection{Panorama de gobernabilidad comunitaria.}

El panorama de la gobernabilidad comunitaria es bastante más complejo, sobre todo porque implica comprender la variedad de la misma y sus

9 Sin embargo su presencia es particular. Por ejemplo, en El Tarra hay una estación fuertemente blindada con sacos de arena y lonas negras para evitar el lanzamiento de granadas a su interior y la visibilidad de sus policías ante el posible accionar de francotiradores. La imagen se repite frecuentemente en los demás poblados de la zona. 
relaciones con el Estado; que a diferencia con la gobernabilidad armada donde el Estado se plantea en flagrante oposición, por lo menos desde lo conceptual, aquí existe un panorama más ambiguo. Así, se hacen presentes en el Catatumbo tres maneras de gobernabilidad comunitaria: una étnica, una comunal y otra de movimiento social. La primera está ligada a las comunidades indígenas y las últimas a las comunidades campesinas.

Los indígenas de la comunidad Motilón Barí tienen sus acciones en sus resguardos ubicados mayoritariamente en la zona norte de la región. Actualmente podría decirse que poseen una autonomía considerable y vienen realizando un trabajo arduo en el rescate de sus tradiciones y formas propias de habitar sus territorios ante la anulación sistemática y continua de su identidad a lo largo del tiempo. Su interacción con los grupos armados ha sido de bastante independencia, puesto que en su mayoría estos grupos respetan sus autonomías y jurisdicciones. La relación con los campesinos, no obstante, es más compleja, sobre todo por los conflictos por límites para el uso de las tierras y la presencia de cultivos de $\operatorname{coca}^{10}$ (Carvajal, 2016).

Por otro lado, al abordar el campesinado en aras de pensar las gobernabilidades híbridas se hace necesaria una mención a la relación entre el Estado cuando interactúa con alteridades ${ }^{11}$ o formas autónomas campesinas presentes en el país. Un elemento clave al respecto es la representación del Estado hacia los campesinos en estas zonas de conflicto, donde se les ve, mayormente, como: i) grupos influenciados e infiltrados de las guerrillas, o como ii) objetos de atención y asistencialismo, pero casi nunca como sujetos y agentes propios (Ortega, 2018). Las representaciones de este tipo son de vital importancia a la hora de comprender los resultados de la interacción entre el Estado y la sociedad civil puesto que determina la postura con que el Estado les abordará.

\footnotetext{
${ }^{10}$ Aunque la presencia de grupos armados no deja de ser conflictiva y problemática para ellos, por la posibilidad de muerte de sus integrantes en fuego cruzado o la siembra de minas antipersonas que imposibilitan el tránsito por sus propios territorios como acostumbran. La presencia de campesinos puede resultar así aún más problemática, porque se asume que su presencia en territorios de los resguardos para, por ejemplo, el cultivo de hoja de coca; incentiva la llegada de grupos armados a sus territorios por la pretensión de regulación de estas economías.

${ }^{11}$ En palabras de Rita Segato (2007).
} 
Ahora, del campesinado en su relación con demás grupos como los indígenas y su lucha por un estatus y reconocimiento, el panorama es más o menos el siguiente: los aprendizajes para la formación de estructuras autónomas han sido complicados, pero se tiene propuestas más o menos concretas valiéndose de sus propios aprendizajes, de su interacción con los grupos armados ${ }^{12}$, y de las experiencias de las demás colectividades. En Colombia, a través de un proceso de reconfiguración identitaria continua, los grupos como los afrocolombianos y los campesinos han recogido parte de la experiencia de los indígenas en las ganancias de autogobierno; exigiendo un trato jurídico similar que parte tan solo de un reconocimiento nominal de su autonomía y sus instituciones propias.

Esto trae consigo una variedad de dificultades por las implicaciones de adoptar modelos, dadas las circunstancias, que se apoyan en la "etnización" de grupos diferentes (Sánchez, Vázquez y Vargas, 2011). Con los campesinos la tensión radica en los criterios para el reconocimiento de sus autonomías: se parte de su carácter identitario con un quehacer económico, el campesinado como personas trabajadoras del campo, pero con particularidades socioculturales. Ante ello, el hecho de no tener una identidad 'étnica' les ha hecho menos propios al reconocimiento de estas formas de autonomías. Y, sin embargo, se han planteado luchas por lograr la amplitud del reconocimiento de sus autonomías a través de espacios como las conocidas Zonas de Reserva Campesina. Pero incluso las ZRC, como ocurre con los resguardos indígenas y consejos comunitarios afros, no serían sino la materialización jurídica de esas maneras de gobernabilidad comunitaria preexistentes.

Ahora, como se mencionó, sus gobernabilidades tienen dos expresiones: de movimiento social y comunal. Como movimiento social campesino en el Catatumbo se hacen presentes tres agrupaciones: CISCA, ASCAMCAT y MCP; quienes se han planteado en defensa de plataformas políticas de los campesinos, evidenciadas en la organización y promoción de protestas y paros campesinos en la región; y el apersonamiento en la interlocución sobre las políticas agrarias y de drogas frente a los campesinos cocaleros ${ }^{13}$.

\footnotetext{
${ }^{12}$ En su dimensión política, los grupos armados han fomentado formas organizacionales con diversos resultados.

${ }^{13}$ Sobre este tema en particular ver Ortega (2018).
} 
El ejercicio práctico de sus intenciones los enfrenta a muchas dificultades. Sobresale como dificultad el ejercicio de la movilización social en un territorio como el Catatumbo, sobre todo para estas tres agrupaciones, que han sido blancos de constantes estigmatizaciones por parte del Estado al culparlos de tener relación directa con los grupos armados.

De otro lado, el movimiento comunal rescata la existencia de las Juntas de Acción Comunal en la división político-administrativa de Colombia, para generar plataformas comunitarias de intervención en cada una de sus veredas, corregimientos o municipios; y parecen estar más ligados a las asociaciones encargadas desarrollo de proyectos productivos comunitarios. Aglutinan así el interés de la población y se enfocan más en el trámite de la vida cotidiana comunitaria por sobre la movilización social.

No obstante, las marcadas fronteras entre unos y otros son ante todo analíticas. A pesar de sus diferencias, varias de las personas que participan en una forma -movimiento social- participan en la otra -comunal-, aunque también hay quienes se mantienen al margen de la pertenencia en los grupos de movimientos sociales, pero no se desentienden del quehacer comunitario y optan así solo por la acción comunal. Y es que las tensiones entre ambas formas, y entre los movimientos sociales, están constantemente a flor de piel. Se resalta sí, que en el panorama más reciente del conflicto armado en la región se creó una plataforma de protección y reclamo por la violación de derechos humanos hacia la población, en la que se unen por primera vez los tres movimientos sociales y el movimiento comunal. Sobre esta plataforma denominada Comisión por la Vida y por la Paz se volverá más adelante.

Ahora, analizando los fines, la apuesta de las gobernabilidades desde la sociedad civil en el Catatumbo se da a dos vías: i) como resistencia a los órdenes políticos en tiempos de guerra y las gobernabilidades armadas, y ii) como alternativa y respuesta ante las formas conflictivas de relación con el Estado. En la segunda vía se han formado repertorios en los siguientes espectros: 1) de interacción directa con el Estado; 2) de reclamo y oposición a sus acciones y omisiones; y 3) de regulación, gobernabilidad y agencia autónomas frente al Estado y las gobernabilidades armadas.

Existen ejemplos de gobernabilidad comunitaria en cada espectro. En interacción con el Estado han existido espacios de interlocución y construcción conjunta, cuya experiencia más representativa ha sido la Mesa 
de Interlocución y Acuerdo del Catatumbo (MIA-C) como espacio regional con representantes de la gobernación, los movimientos sociales y entidades externas como Naciones Unidas. La valoración de un espacio como estos resulta positiva para los fines propuestos en este artículo; pero sus limitantes están: el funcionamiento de la MIA-C es fluctuante y coyuntural, y la mayoría de veces se queda en un espacio de interlocución de posturas e intenciones.

En acciones de reclamo y oposición al Estado destacan las marchas y paros campesinos. El hito de protesta en la región fue el paro del 2013 en el que se reclamaba contra la criminalización por parte del Estado, se pedía el reconocimiento de una Zona de Reserva Campesina en el Catatumbo y un manejo diferenciado de la problemática de cultivos de uso ilícito (Cruz, 2017). Este paro que tuvo duración de un par de meses, devino en acuerdos con el gobierno que posteriormente se incumplirían. El incumplimiento de estos acuerdos ha generado un círculo vicioso de protesta-negociaciónacuerdo-incumplimiento-protesta (Carvajal, 2016; Carvajal, Gutiérrez, y Ortega, 2019).

Pero mantener las capacidades de movilización con fines de reclamo es complicado. En fechas más recientes, el 25 de abril de 2019, se da una de las últimas protesta en el marco de un paro nacional, presentando menor participación de algunos movimientos sociales como Ascamcat debido al desgaste de sus capitales políticos tras años de representatividad fallida ${ }^{14} \mathrm{y}$ por falta de garantías a la integridad física, teniendo en cuenta los últimos acontecimiento de violencia en la región.

Por último, están las acciones relativas a la regulación, gobernabilidad y agencia autónomas frente al Estado y las gobernabilidades armadas. Frente al Estado estas se proponen sobre todo en respuesta de su presencia diferenciada y la desarticulación con la vida económica y política nacional. Como ejemplo, por parte de los movimientos sociales, se tiene el mantenimiento de vías. En ello en particular el Cisca se ha encargado, junto a la población en general y los demás movimientos, de promover una intervención autónoma de cuidado y arreglo de la vía principal que atraviesa el Catatumbo entre los municipios de El Tarra y Convención. A lo largo de

\footnotetext{
${ }^{14}$ Especialmente el desgaste viene a darse por el papel que el movimiento ha tenido a favor del fallido Plan Nacional Integral de Sustitución de Cultivos de uso ilícito.
} 
este trayecto de vía rudimentaria, sin asfalto y propensa en ciertos lugares a derrumbes, existen tres peajes comunitarios que cobran una tarifa aproximada de 5.000 pesos colombianos por automóvil (Observación y entrevistas pobladores, 2018).

El cobro se realiza en única ocasión por viaje. Una vez cobrado en uno de los tres puntos este impuesto comunitario, quien conduce recibe una boleta que debe mostrar en los siguientes puntos -en caso de completar todo el trayectopara que no se le cobre nuevamente. El dinero se usa para un mantenimiento reflejado en la el trabajo continuo de algunas maquinarias pesadas adquiridas para estos fines, que se encargan de aplanar el terreno lo más posible y destapar la vía en caso de derrumbes.

En otro lado, Ascamcat ha encabezado la promoción de la Zona de Reserva Campesina del Catatumbo que busca formas propias de relación del campesinado con el territorio en reclamo de: formalidad en los predios, coexistencia del modelo económico campesino y agroindustrial y solución de los conflictos territoriales con los resguardos indígenas (Prensa Rural, 2016). Mientras la disputa por el reconocimiento de la zona se mantiene, la creación de facto va andando acompañada también de proyectos como la Guardia Campesina $^{15}$ : cuerpos no armados revestidos de autoridad, que se encargan de vigilar y gestionar la convivencia en los territorios, cumpliendo labores similares a los de la policía, pero sin recurrir a métodos coercitivos propios de estos cuerpos del Estado ni de los grupos armados.

Por su parte, desde el movimiento comunal -también con injerencia y promoción de los movimientos sociales- se promueve la consolidación de proyectos productivos comunitarios autogestionados. En las veredas y corregimientos se han ido creando asociaciones productivas con base en la producción de cacao, siembra de pescado y otros productos agropecuarios, como búsqueda de alternativas económicas estables, y de plantear una semilla de oposición desde la práctica sobre las economías asociadas a la ilegalidad como la siembra de cultivos de uso ilícito. La promoción de esto último es una de los ejemplos que develan con más claridad la apuesta autónoma y gobernabilidad propia en antagonismo y desencuentro con las otras dos gobernabilidades en el territorio -la armada y la estatal-: la gobernabilidad de

\footnotetext{
${ }^{15}$ Este cuerpo de control y seguridad comunitario es otro de los legados que el movimiento indígena ha dado a las alteridades campesinas y afrodescendientes.
} 
los grupos armados se propone muchas veces en oposición a estas alternativas económicas, a través de amenazas y prohibiciones de producción; y la estatal afianza el desentendimiento o el acompañamiento esporádico y cortoplacista sin resultados claros y esperados. La opción radica en afianzar los proyectos productivos, por un lado, con la interlocución y legitimidad de la población respecto a los grupos armados, y de gestión recursos con independencia del gobierno por el otro, generando contacto directo de las asociaciones productivas con cooperación internacional, agencias de Naciones Unidas o entidades como la Pastoral Social de las Iglesias locales.

Para dar mención a ejemplos en la vía de resistencia a las gobernabilidades armadas, a lo largo del 2018 inicia una confrontación entre el ELN y el EPL con fuertes repercusiones sobre la población civil (confinamiento, desplazamiento, muertes directas, entre otras). En el ejercicio de lo aquí denominado gobernabilidad comunitaria, se dio que los movimientos sociales y comunales se unieron de forma atípica para la conformación de la Comisión por la Vida y la Paz con actividades diversas: desde entablar conversaciones directas con los grupos armados solicitando el cese de las confrontaciones (Verdad Abierta, 2018), o apelando a formas de seguridad y asistencia colectiva, como el acompañamiento masivo a ambulancias que transportan heridos o la construcción de refugios para los desplazados internos de las confrontaciones (El Espectador, 2018). Sobre este tipo de asuntos la población civil juega un rol primario de autocuidado al punto de extender la resistencia a las expresiones armadas de la gobernabilidad estatal, quienes a través de la Fuerza Pública han jugado un papel cuestionable en el cuidado del DIH y Derechos Humanos ${ }^{16}$.

\section{Hacia el fortalecimiento de la hibridez.}

González (2016) en su presentación sobre el concepto de gobernabilidades híbridas explica:

[...] la propuesta de gobernabilidades híbridas supondría combinar la institucionalidad estatal con formas regulatorias, que pueden ser

\footnotetext{
${ }^{16}$ Véase el caso de la muerte de Dimar Torres y la respuesta de la institucionalidad estatal y la sociedad civil: International Action for Peace (2019) Conflicto en activo, Catatumbo en resistencia [en línea] disponible en: https://www.actionpeace.org/conflicto-activocatatumbo-resistencia/
} 
autoritarias, clientelistas o comunitaria, que tienen algún grado de legitimidad o aceptación por parte de las poblaciones [...] (p.51).

Y sobre sus implicaciones expresa:

Esto implicaría reconocer la posibilidad de que actores no estatales, incluso armados, y políticos de corte clientelista contribuyan de alguna manera al fortalecimiento de la institucionalidad estatal, tal como se combinan gobiernos locales autoritarios con estados centrales más democráticos y tecnocráticos, [...] (p.51).

[...] la experiencia de regulaciones de tipo comunitario, más cercanas a la interacción con las comunidades del estilo de la gobernanza, permitiría introducir mejoras a la gobernabilidad del orden local al permitir a la lógica estatal funcionar en el nivel submunicipal de las veredas. Al tiempo, la institucionalización de estas prácticas de regulación comunitaria permitiría proyectar la lógica de gobernanza en los gobiernos locales para ir superando la tradicional mentalidad antipolítica de algunos actores sociales de esos niveles [...] (p.51).

La forma acertada en que se recoge esta propuesta tiene sus bemoles a la luz de la finalidad con que se promueve este ideal, sobre todo en dos puntos clave. Lo primero es la propensión única de ver en los resultados de las gobernabilidades híbridas el crecimiento y fortalecimiento del Estado, así sea el Estado en lo local; lo segundo atañe a la dificultad que la hibridez propone para el concepto mismo del Estado.

Frente a lo primero no se puede negar que las gobernabilidades híbridas, por su propia hibridez, promueven el cumplimiento del papel del Estado, pero observar como implicación central el fortalecimiento de su gobernabilidad desconocería que así mismo la aplicación de modelos híbridos debe conllevar a un fortalecimiento por lo menos de la gobernabilidad comunitaria.

Se habla de "por lo menos", ya que las gobernabilidades armadas son más difíciles de tramitar para el Estado, toda vez que 1) la relación abierta con ellas se hace por debajo de mesa, debido al marco jurídico que imposibilita al Estado mismo el reconocimiento de estas gobernabilidades, y 2) la existencia de la responsabilidad de parte del Estado por la búsqueda de la paz y el 
mantenimiento del orden público ${ }^{17}$. Mientras, la gobernabilidad clientelar hace parte del funcionamiento estatal, aunque no se reconozca de forma plena su carácter funcional para poder actuar desde él, y de plantear acciones para la superación de sus condiciones como garantía del proyecto de ciudadanía normativamente promovido por el mismo Estado; y finalmente, la gobernabilidad comunitaria, en un panorama en que al Estado se le dificulta reconocer lo comunitario en regiones como el Catatumbo ${ }^{18}$, en detrimento de la función democrática propia de la realidad colombiana y latinoamericana que supone la existencia de estos proyectos de autogestión comunitaria.

Para esto concierne abordar el segundo punto: la dificultad que la hibridez propone para el concepto mismo del Estado. Es innegable la tensión conceptual que el mero reconocimiento de estas gobernabilidades supone para la estatalidad, y más aún la solicitud expresa de hacerle actuar a partir de una interseccionalidad con ellas (González, 2016). La dificultad no radica en que en una región no haya el suficiente Estado; el problema radica en el momento en que el Estado busque robustecer sus instituciones en estos lugares sin reconocer las formas de organización social y políticas propias e intente suprimirlas.

Este procedimiento resulta fácil de justificar al intentar suprimir la gobernabilidad autoritaria de los grupos armados recobrando para sí el monopolio de la fuerza; pero la propuesta de gobernabilidades híbridas llama a comprender las dimensiones de la presencia de grupos armados, reconociendo su carácter regulador y abandonando lecturas reduccionistas que solo se centran en la depredación de recursos por parte de estos grupos.

Correspondiente a las gobernabilidades comunitarias, comprender que estas formas autónomas de la sociedad civil no surgen sólo para, ni tienen como fin, aprovecharse del vacío que deja un Estado “ineficiente”. Esto supondría que dicha gobernabilidad debe y puede ser suprimida en el momento en que el Estado fortalezca sus instituciones en estos territorios. Pretende más bien darle a entender al Estado la incapacidad de tramitar el ejercicio de órdenes sociales más allá de sus propios criterios; en el que las comunidades se dan a

\footnotetext{
${ }^{17}$ Y precisamente, en pro de la búsqueda de alternativas viables para esa búsqueda de la paz es que se debe reconocer el papel de las gobernabilidades armadas en los territorios.

${ }^{18}$ Reconocimiento engorroso si se combinan variables de lo comunitario campesino en estas zonas donde se incluyen actividades como la siembra de cultivos de uso ilícito. Sobre estas dificultades véase a Ortega (2018).
} 
sí mismas la posibilidad de ejercer política, social, económica y culturalmente una alteridad negada por el abandono y, cuando hay presencia, por la intervención estandarizante del Estado.

Por tanto, a riesgo de estiramiento y alcance teórico, toda esta discusión se alimenta también de los estudios decoloniales que desde múltiples vertientes de las ciencias sociales de América Latina se han ido desarrollando. Por ejemplo, la crítica al Estado moderno por la incapacidad de comprender e incluir las alteridades tradicionalmente excluidas por parte de Rita Segato (2007), entre otras autorías. Por tanto, las gobernabilidades comunitarias pueden ser percibidas como una respuesta firme de la sociedad civil de apostar por la construcción de sus autonomías, sin solicitar en pleno la autorización del Estado para el ejercicio de sus prácticas, aunque siempre se estará en constante relación y tensión con este.

Sobre esto los espectros de acción son múltiples. Incluyendo todas las gobernabilidades -incluso la armada-, espacios como los procesos de paz son una oportunidad para darle contenido a la hibridez. El panorama de deslices en la puesta en marcha del Acuerdo Final con las Farc y la ruptura con la mesa de diálogos del ELN ponen en duda un escenario cercano de esta naturaleza; pero basta observar el trámite de la Comisión por la Vida y la Paz a la confrontación entre el EPL y el ELN para observar cómo las realidades regionales desembocan en espacios híbridos. En la relación estatalidadsociedad civil, experiencias como la MIA-C, en algunas investigaciones catalogada como ejercicio de gobernanza radical (Ortega, 2018), puede también dar pistas de las experiencias construibles en esta materia.

Los eventuales espectros de acción van llevando a las conclusiones del texto, unidas a un llamado por la creatividad para alargar la lista del párrafo anterior a sabiendas de la importancia de rastrear estas experiencias. No es solo reconocer y entender los órdenes políticos en tiempos de guerra gobernabilidad armada-, las redes clientelares, las gobernabilidades propias de la sociedad civil y la presencia diferenciada del Estado; hay que tramitar un conocimiento más profundo de las interseccionalidades de estas formas de gobernabilidad en territorios afectados por el conflicto armado. Sabiendo además que estas interseccionalidades se extienden a coyunturas donde no es necesaria la vigencia de un conflicto como el colombiano: se pueden pensar sus impactos en casos de alta criminalidad y grupos armados varios como en El Salvador o México, teniendo en cuenta que por más que se le intente 
relegar a un papel depredador, los fenómenos de criminalidad organizada también generan formas sociales y políticas en los territorios.

La comprensión de esta interseccionalidad se propone como alternativa para Latinoamérica y Colombia ante la visión moderna para la solución de los problemas que atañen al papel del Estado y su formación deficiente; según la cual, luego de reconocer los límites del proceso histórico de su creación que terminan en una presencia diferencial estatal, la mayor alternativa es fortalecerlo a como de cabida. No se desconoce el papel que el Estado colombiano posee, ni sus responsabilidades como amalgamador de un proyecto político y social para el caso llamado Colombia; pero bajo esta óptica, el cumplimiento de las responsabilidades del Estado a partir, únicamente, de su fortalecimiento, supone no reconocer la condición híbrida del asunto en cuestión.

Por último, recoger uno de los aportes de esta intervención académica. El fin del artículo no ha sido solo el de presentar una lectura más allá de la Captura del Estado y de complejizar el panorama de acción estatal ante sus múltiples falencias. También se ha sugerido una tipología que recoja las experiencias académicas en Colombia y el paso por una región como el Catatumbo. Ante el llamado de generar gobernabilidades híbridas y transformar la acción y comprensión del Estado ante las alteridades que niega, se ha propuesto la categoría de Formas de gobernabilidad autónomas -gobernabilidad armada, gobernabilidad clientelista, gobernabilidad comunitaria-; sobre esta última gobernabilidad se insiste en un llamado por la ampliación de investigaciones que den contenido a las experiencias comunitarias, recogiendo la riqueza de sus diversas expresiones, que se intentan recoger en la siguiente categorización: i) gobernabilidad autónoma comunitaria étnica, ii) gobernabilidad autónoma comunitaria comunal y iii) gobernabilidad autónoma comunitaria de movimiento social; ampliable o reducible según los resultados de estas lecturas futuras. 


\section{Bibliografía}

Aponte, A. (2012). Cúcuta y el Catatumbo: entre la integración y la marginalización. Disputas territoriales, arreglos institucionales $e$ imposición de un orden social de la guerra. En Conflicto y territorio en el Oriente colombiano. Fernán González et. al. ODECOFI-CINEP. Bogotá

Arjona, A. (2016). Rebelocracy. Cambridge University Press.

Barrera, V., Coronado, S., Hoyos, C., Guzman, T., \& Garcia, M. (2016). Tendencias de la movilización social en municipios críticos para el posconflicto CINEP.

Carvajal, C. (2016) Lecturas territoriales en clave de paz. región del Catatumbo, Cinep, Redprodepaz.

Carvajal, C.; Gutiérrez, E. y Ortega, H. (2019). Capítulo Catatumbo, en: Conflictos sociales y perspectivas sobre la paz completa en regiones con presencia del ELN. CINEP. Diakonia. (En proceso de publicación).

Cepeda, C. (2015). Resistencias contra el neoliberalismo: Entre lo local y lo global.

Comisión Histórica del Conflicto y sus Víctimas. (2015). Contribución al entendimiento del conflicto armado en Colombia. Ediciones Desde Abajo.

Cinep (2017) Viabilidad y alternativas para la implementación del Plan Nacional Integral de Sustitución de Cultivos de uso ilícito. Una mirada regional desde el Catatumbo (Norte de Santander). Bogotá.

Cruz Rodríguez, E. (2017). La protesta campesina en el Catatumbo Colombia (2013). Un análisis sociopolítico. Mundo Agrario, 18 (39), e073. https://doi.org/10.24215/15155994e073

El Espectador (2018) Tras un mes de enfrentamientos el Catatumbo está quedando desolado [en línea] disponible en: https://www.elespectador.com/colombia2020/pais/tras-un-mes-deenfrentamientos-el-catatumbo-esta-quedando-desolado-articulo-856567

Entrevista experto regional (2019) Entrevista sobre situación de cultivo de palma en la región del Catatumbo. Cúcuta. 2019. 
Garay, L. J., Salcedo, E., \& De León, I. (2008). La reconfiguración cooptada del Estado: más allá de la concepción tradicional de captura económica del Estado. Bogotá, Corporación Transparencia por Colombia.

González, F. (2003). ¿Colapso parcial o presencia diferenciada del estado en Colombia?: Una mirada desde la historia. Colombia Internacional. Universidad De Los Andes, 124-158.

González, F. (2014). Poder y violencia en Colombia. Editorial Pontificia Universidad Javeriana.

González, F. (2016) ¿Gobernabilidades híbridas o gobernanza institucionalizada en Colombia? Elementos para pensar la paz territorial en un escenario de transición. REVISTA CONTROVERSIA, (206).

González, F., Bolívar, I. J., \& Vázquez, T. (2003). Violencia política en Colombia: de la nación fragmentada a la construcción del Estado. Centro de Investigación y Educación Popular.

Gutiérrez Sanín, F. (2007). ¿Lo que el viento se llevó?: los partidos políticos y la democracia en Colombia, 1958-2002. Editorial Norma.

Guzmán, G., Fals Borda, O., \& Umaña, E. (1962). La violencia en Colombia. Estudio de un proceso social, 2, 1962-64.

Leal, F., \& Dávila, A. (1990). Clientelismo. El sistema político y su expresión.

Leal Buitrago, F., \& Dávila Ladrón de Guevara, A. (2010). Clientelismo: el sistema político y su expresión regional. Ediciones Uniandes-Universidad de los Andes.

Observación y entrevistas pobladores (2018) Visita de campo y entrevista a pobladores del Catatumbo. Enero, 2018.

Oquist, P. (1978) Violencia, política y conflicto en Colombia, Bogotá: Instituto de Estudios Colombianos, Biblioteca del Banco Popular.

Ortega, H. (2018) ¿Con las manos amarradas? Los retos para la participación de la sociedad civil en el Plan Nacional Integral de 
Sustitución de cultivos de uso ilícito. Tesis de pregrado. Pontificia Universidad Javeriana.

Prensa Rural (2016) La Zona de Reserva Campesina del Catatumbo: una inciativa del campesinado que quiere la paz [en línea] disponible en: https://prensarural.org/spip/spip.php?article18687

Sánchez, G., \& Meertens, D. (1983). Bandoleros, Gamonales y Campesinos: el caso de la violencia en Colombia. Bogotá: El Áncora

Sánchez, Vásquez y Vargas (2011) Capítulo 2. Las diversas trayectorias de la guerra: un análisis subregional. En: Restrepo, Vásquez y Vargas (2011) Una vieja guerra en un nuevo contexto: conflicto y territorio en el sur de Colombia. Odecofi. Bogotá.

Segato, R. L. (2007). La nación y sus otros: raza, etnicidad y diversidad religiosa en tiempos de políticas de la identidad. Prometeo Libros Editorial.

Staniland, P. (2012). States, insurgents, and wartime political orders. Perspectives on politics, 10(2), 243-264.

Verdad Abierta (2018) El Catatumbo resiste a la guerra con su Comisión por la Vida [en línea] disponible en: https://verdadabierta.com/catatumboresiste-la-guerra-comision-la-vida/ 